\title{
Optimization of temperature conditions for the growth of large-size sapphire crystals by the method of horizontally directed crystallization
}

\author{
L.A.Grin, A.T.Budnikov, N.S.Sidelnikova, \\ G.T.Adonkin, V.V.Baranov \\ Institute for Single Crystals, STC "Institute for Single Crystals", \\ National Academy of Sciences of Ukraine, \\ 60 Lenin Ave., 61001 Kharkiv, Ukraine
}

Received November 10, 2012

\begin{abstract}
The coefficient of dislocation gliding over the planes of easy glide depending on the shape of the crystallization front, is determined. The regions of non-uniform distribution of thermal field in the crystal are established. Optimized are the temperature conditions for the growth of large-size $\left(350 \times 500 \times 45 \mathrm{~mm}^{3}\right)$ sapphire crystals by the method of horizontally directed crystallization. The change of the density of dislocations and of their distribution in the crystal bulk after correction of the technological growth conditions, is considered. It is shown that optimization of the axial, horizontal and vertical components of the temperature gradient makes it possible to improve uniformity of the thermal field distribution at the crystallization front in the process of the stationary crystal growth.
\end{abstract}

\footnotetext{
Оценена степень выклинивания дислокаций по плоскостям легкого скольжения в зависимости от формы фронта кристаллизации по ширине и толщине кристалла. Проведено моделирование распределения тепловых полей в кристалле для двухмерной модели. Определены участки нелинейного распределения теплового поля по ширине и толщине кристалла. В результате оптимизированы температурные условия для выращивания крупногабаритных $\left(350 \times 500 \times 45 \mathrm{~m} \mathrm{м}^{3}\right)$ кристаллов сапфира методом ГНК. Рассмотрено изменение плотности дислокаций и их распределение по объему кристалла после внесения коррекции в технологический режим выращивания. Показано, что оптимизация осевой, горизонтальной и вертикальной составляющих градиента температуры приводит к улучшению равномерности распределения тепловых полей на фронте кристаллизации после стадии разращивания кристалла.
}

\section{Introduction}

Recent few years have seen keen interest of the world market to large-size sapphire single crystals, special-purpose wide-aperture optical sapphire elements, as well as functional elements for micro- and optoelectronics. In this connection, one of the main problems confronting sapphire producers is the increase of the size of the grown crystals with their high structure perfection and optical quality remaining unchanged over the whole of the crystal bulk.

As is well-known [1], the structure perfection of corundum single crystals essentially depends on the growth conditions and orientation of the seed crystal with respect to the crystallization front. The latter influences the degree of gliding of the dislocations formed in the process of crystal growth. This is most often observed for the surface plane $(0001)$. In this case the main contribution to the evolution of the disloca- 
tions belongs to the prismatic system of sliding. Critical shear stresses in this system are by an order higher than those in other systems (the basic and rhombic) [2]. The dislocations of the prismatic system cause the formation of low-angle boundaries which then may form a structure containing macroblocks.

Other conditions influencing the structural and optical characteristics chiefly depend on the growth method. The main factors which give rise to the formation of defects in the process of crystal growth by the method of horizontally directed crystallization (HDC) in protective gaseous medium are: 1) the purity of the raw material; 2) the pressure and composition of the medium over the melt; 3 ) the growth rate; 4) the temperature gradients (along and perpendicular to the growth direction); 5) the orientation of the planes of easy glide with respect to the growth direction (the interface shape); 6) stability of the thermal conditions during the growth [1]. The method of HDC made it possible to obtain corundum single crystals of high structure and optical quality with the dimensions $200 \times 200 \times 35 \mathrm{~mm}^{3}$ and different surface orientation [3]. In our opinion, further increase of the crystal dimensions may essentially disturb stability of the thermal growth conditions. Therefore, in the present work the last three of the above-said factors are considered in detail.

The goal of this study was to determine optimum conditions for the growth of large sapphire single crystals with the dimensions reaching $350 \times 500 \times 45 \mathrm{~mm}^{3}$ by the method of $\mathrm{HDC}$ in weakly reducing medium.

One of possible ways for solving the set task is a detailed consideration of the horizontal and vertical components of the temperature gradient in the zone of crystal growth and, consequently, the orientation of the planes of easy glide with respect to the crystallization front. This will permit to diminish the quantity of structure defects in the crystal in the process of its growth.

The other direction of the investigation is the simulation of the temperature fields in the zone of crystal growth and annealing. There exist few papers devoted to the simulation of the temperature fields for the method of HDC [4-6]. For the technology of the growth in weakly reducing protective medium such calculations have not been made so far. Consideration of the shape of the crystallization front and of the distribution of the thermal field in the grown crystal will make it possible to determine the segments characterized by high probability of the formation of structure defects and the ones with high values of thermoelastic stresses.

\section{Experimental}

The investigation was performed on $350 \times 500 \times 45 \mathrm{~mm}^{3}$ sapphire crystals grown under the conditions of dynamic pumping by the method of HDC in reducing atmosphere $\left(\mathrm{CO}+\mathrm{H}_{2}\right)$ under a total pressure of 10-30 Pa. The seed crystal chosen for the

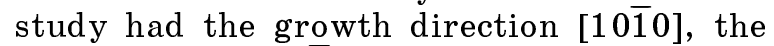
side surface $(1 \overline{12} 0)$ and the upper plane (0001). The growth rate was $8-10 \mathrm{~mm} / \mathrm{h}$.

As mentioned above, one of the conditions for the obtaining of sapphire with low dislocation density is high purity of the raw material. Therefore, the material used for the growth of large-size crystals contained minimal quantity of impurities (Table 1).

During the growth process the axial temperature gradient $\left(G^{\mathrm{a}}\right)$ varied from 20 to $10^{\circ} \mathrm{C} / \mathrm{cm}$. The temperature gradients perpendicular to the growth direction - the horizontal $\left(G^{\mathrm{h}}\right)$ and vertical $\left(G^{\mathrm{v}}\right)-$ varied from 10 to $0^{\circ} \mathrm{C} / \mathrm{cm}$ and from 0 to $15^{\circ} \mathrm{C} / \mathrm{cm}$, respectively. The temperature measurements were carried out using a two-beam integral pyrometer "Marathon MR1SCSF" and tungsten/rhenium thermocouples.

An important role in the formation and motion of the dislocations belongs to the spatial orientation of the seed with respect to the crystallization front [7]. In [8] there was introduced the parameter $k$ (the coefficient of dislocation inheritance) corresponding to the quantity of the dislocations which remain in the crystal after the process of dislocation gliding:

$$
k=1-(\delta / D),
$$

where $\delta$ is the distance to the surface which allows gliding of the dislocations from the crystal bulk in the zone of plasticity; $D$ is the crystal width.

However, at the presence of several planes of easy glide with different angles of

Table 1. Content of main impurities in $\alpha-\mathrm{Al}_{2} \mathrm{O}_{3}$, mass. $\%$

\begin{tabular}{|c|c|c|c|c|c|c|c||}
\hline \hline $\mathrm{Fe}$ & $\mathrm{Si}$ & $\mathrm{Mg}$ & $\mathrm{Ti}$ & $\mathrm{Mn}$ & $\mathrm{Ca}$ & $\mathrm{Na}$ & $\mathrm{K}$ \\
\hline$<\mathbf{0 . 0 0 0 4}$ & $<\mathbf{0 . 0 0 2}$ & $<\mathbf{0 . 0 0 0 2}$ & $<\mathbf{0 . 0 0 0 5}$ & $<\mathbf{0 . 0 0 0 0 5}$ & $<\mathbf{0 . 0 0 0 5}$ & $<\mathbf{0 . 0 0 1}$ & $<\mathbf{0 . 0 0 2}$ \\
\hline
\end{tabular}


the slope towards the crystallization front and different probabilities of the process of gliding this parameter is not informative enough [9]. But it can be substituted by another parameter, i.e. the coefficient of dislocation gliding $(K)$ which takes into account all the planes of easy glide and their location with respect to the crystallization front in different parts of the crystal:

$$
K=\sum_{i}(\delta / D),
$$

where $\sum_{i}$ is the sum taken over the planes of easy gliding.

Under the given growth conditions, the probability of dislocation gliding will have different values for different parts of the crystal. This is caused by the changes in the crystallization front bending in the region of the increase of the crystal size (the change of $G^{\mathrm{h}}$ ) and in the slope of the front towards the crucible bottom (the change of $G^{\mathrm{v}}$ ). Thereat, the main contribution to the dislocation evolution belongs to the prismatic glide system. In this connection we considered the orientation of the planes of the said slide system. The optimum angle of the slope of the crystallization front towards the crucible bottom was determined, too.

Before and after the correction of the growth conditions there were determined the dislocation density and their distribution in the bulk in three main segments of the crystal. The dislocation density was measured by the method of selective etching. The density of isolated dislocations was calculated on a MIC-4 microscope and then averaged over 10 fields of view (the area of each field was $2 \mathrm{~mm}^{2}$ ).

\section{Results \& discussion}

High values of the axial $\left(G^{\mathrm{a}}\right)$ and horizontal $\left(G^{\mathrm{h}}\right)$ temperature gradient components at the onset of the growth exclude spurious nucleation.

Thereat, the angle between the tangent to the crystallization front and the plane (1010) reaches $50^{\circ}$ (Fig. 1). Later on the growth of the crystal without changes in its size (stationary growth) is realized at a flat or slightly convex interface. Therefore, the

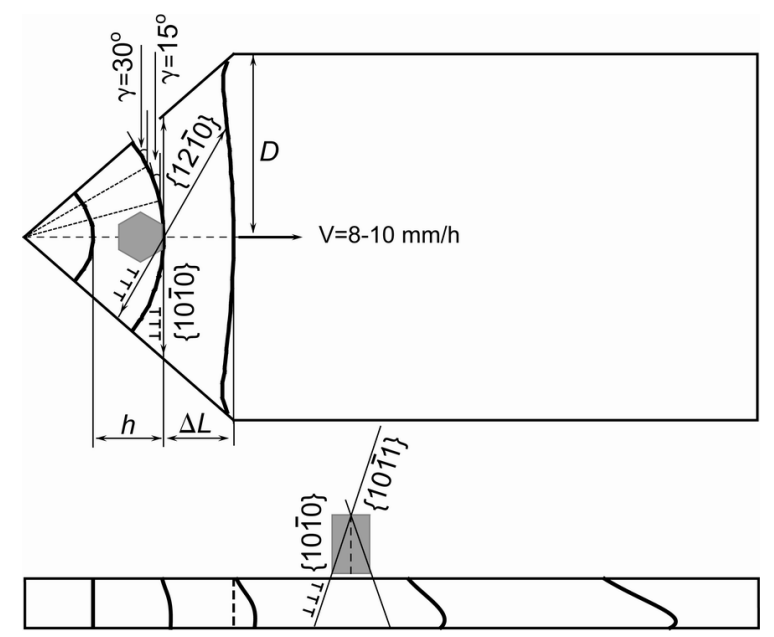

Fig. 1. Horizontal and vertical bending of the crystallization front in the process of crystal growth $(\gamma$ is the angle between the tangent to the crystallization front in different segments of the crystal and the plane (1010); $h$, the region of plasticity; $\Delta L$, displacement of the crystallization front; $D$, the distance from the center of the crystal to its side surface.

radius of the curvature of the crystallization front in the triangular crystal segment changes (Fig. 1).

The coefficient of dislocation gliding was determined with respect to six $\{10 \overline{1} 0\}$ and six $\{11 \overline{2} 0\}$ planes of easy glide according to the formula (2). Since the slopes of the basis and rhombohedral planes towards the crystallization front remained unchanged in this case, they were not taken into account. The calculations were made for the angles formed by the tangent to the crystallization front and the plane $(10 \overline{1} 0)$, with a step of $15^{\circ}\left(0^{\circ}, \pm 15^{\circ}, \pm 30^{\circ}, \pm 45^{\circ}\right)$. For qualitative estimation of the gliding coefficient such calculations are sufficient. Moreover, there were taken into account the probabilities of dislocation gliding in each of the considered planes [9]. The calculation results are presented in Table 2.

As seen from this Table, the highest coefficient of dislocation gliding corresponds to the case when the plane (1010) is parallel to the interface, i.e. when the crystallization front is flat $\left(G^{\mathrm{h}}=0\right)$. This is observed in the region of the stationary crys-

Table 2. Estimated coefficients of dislocation gliding at different angles between the tangent to

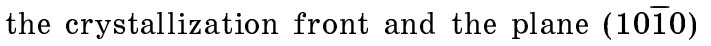

\begin{tabular}{|c|c|c|c|c|c|c|c||}
\hline Angle, deg. & -45 & -30 & -15 & 0 & +15 & +30 & +45 \\
\hline Coefficient of dislocation gliding, a.u. & 8.6 & 9.2 & 8.6 & 11.94 & 8.6 & 9.2 & 8.6 \\
\hline
\end{tabular}




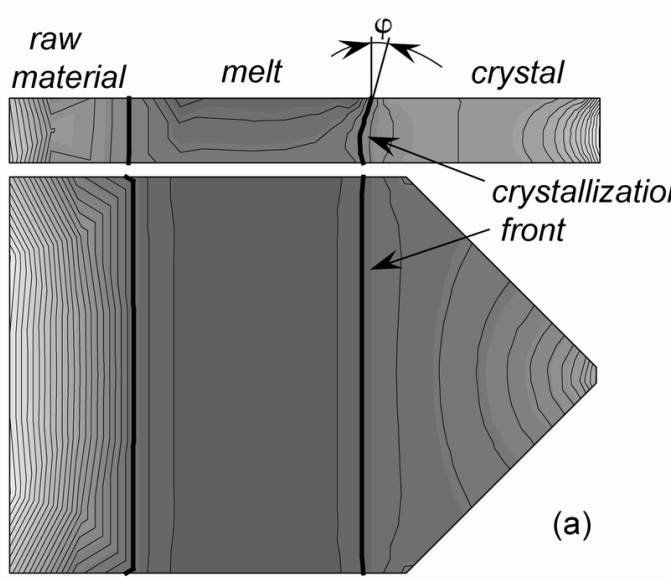

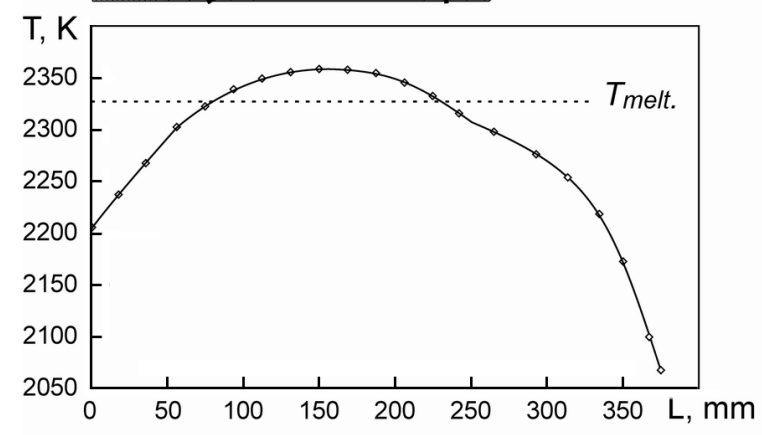

(b)

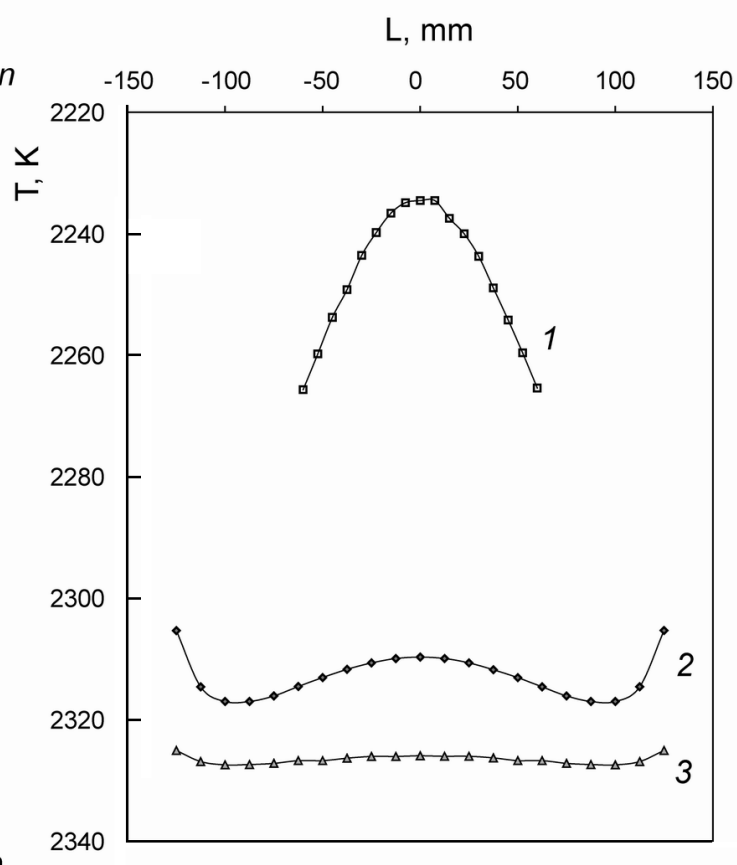

(c)

Fig. 2. Pattern of temperature field in the system "crystal - melt - raw material" calculated using the program ELCUT (a); temperature distribution along the axis of the crucible in the process of crystal growth (b); temperature distribution along the crystallization front (c): 1 - at the onset of crystal growth, 2 - before the stationary growth at a distance of $1 \mathrm{~mm}$ from the crystallization front, 3 - before the stationary growth at a distance of $20 \mathrm{~mm}$ from the crystallization front. The length of the grown crystal segment is $145 \mathrm{~mm}$, the length of the annealing zone is $350 \mathrm{~mm}$.

tal growth. However, in the segment where the crystal size varies the front is convex, and the curvature radius varies $\left(0<G^{\mathrm{h}}<10^{\circ} \mathrm{C} / \mathrm{cm}\right)$. As show the data from Table 2, the coefficient of dislocation gliding is the lowest when the tangent to the crystallization front does not coincide with any of the planes of easy glide (the angles $15^{\circ}$ and $45^{\circ}$ ). At an angle of $45^{\circ}$ the distance to the side surface of the crystal is small, and this raises the probability of dislocation gliding. Therefore, at the growth of sapphire crystals in the direction [10̄10], in the segments where $\gamma=15^{\circ}$ (especially with low values of $G^{\mathrm{a}}$ and $G^{\mathrm{h}}$ ) the formation of structure defects has the highest probability. Such a situation occurs in the region of the change-over to the stationary growth. Thereat, the growth rate must be lowered to extend the time of the stay of the given crystal segment in the zone of plasticity.

In the process of crystal growth in the direction [10 $\overline{10}$ ] the problem of optimization of the slope angle of the crystallization front with respect to the crucible bottom will not be solved unambiguously, due to a large number of factors which influence the formation of the dislocations. However, as seen from the previous estimations, the coefficient of dislocation gliding is essentially higher in the case when the plane of easy glide coincides with the crystallization front. Therefore, it should be concluded that the best conditions for dislocation gliding will be observed at the coincidence of the crystallization front with the plane $(10 \overline{1} 1)$. This is achieved if the condition $0<G^{\mathrm{h}}<5^{\circ} \mathrm{C} / \mathrm{cm}$ is satisfied up to the onset of the stationary crystal growth.

The model calculations were realized by means of the program ELCUT $[10,11]$ using the method of finite elements on inhomogeneous mesh for the calculation of a twodimensional model of thermal and stress field. At first there were estimated the thermal conditions at the growth of the crystals with the rectangular part measuring $250 \times 250 \times 40 \mathrm{~mm}^{3}$. The real temperature distribution in a standard thermal furnace with $350 \mathrm{~mm}$ long annealing zone was 

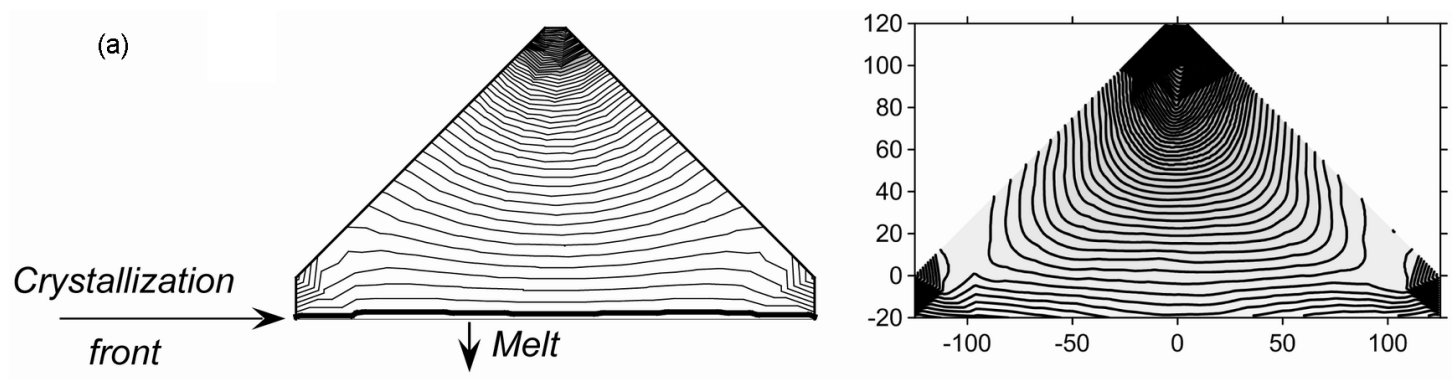

(b)
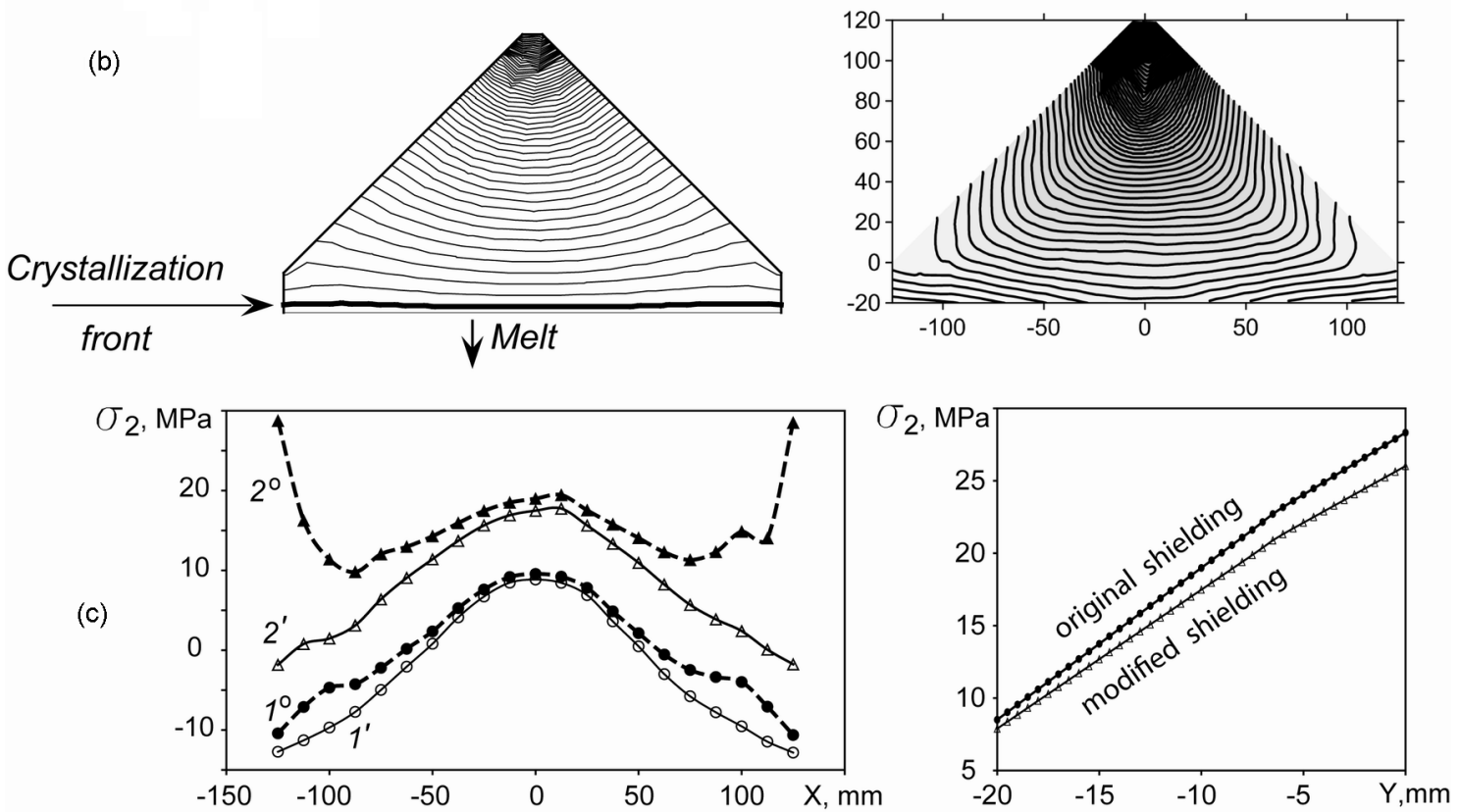

Fig. 3. Temperature field (from the left) and stress field, $\sigma_{2}$ isolines (from the right) in the grown part of the crystal at the standard shielding (a), and at the additional shielding in the region of the change-over from the triangular to the rectangular part of the crucible (b); (c) - the values of $\sigma_{2}$.

measured, and the obtained results were compared with the calculation data. Thereat, the coincidence between them turned out to be satisfactory. The boundary conditions at different crystal growth stages were determined using experimental values of the real temperature distribution in thermal furnace, and numerical estimations of the efficiency of shielding. The final calculations of the temperature fields were carried out for the crystal with the rectangular part measur- ing $350 \times 500 \times 45 \mathrm{~mm}^{3}$. Other parameters for the calculations are presented in Table 3 .

The results of the calculation of the temperature distribution in the system "crystalmelt-raw material" with $145 \mathrm{~mm}$ long part of the grown crystal are shown in Fig. 2 .

The calculation results show a sharp exponential drop of the temperature in the vicinity of the crystallization front. This is characteristic of systems with radiative heat exchange ( $S$-shaped temperature distri-

Table 3. Parameters of materials for model calculations

\begin{tabular}{||c|c|c|c|c||}
\hline Properties of material & Crystal & Melt & Raw material & Molybdenum \\
\hline Density $\left(\mathrm{kg} / \mathrm{m}^{3}\right)$ & 3970 & 3000 & 2800 & \\
Specific heat $(\mathrm{J} / \mathrm{kg} \cdot \mathrm{K})$ & 750 & 1560 & 1620 & 430 \\
Thermal conductivity $(\mathrm{Wt} / \mathrm{m} \cdot \mathrm{K})$ & 10 & 3.5 & 2 & 69 \\
Radiation coefficient & 0.87 & 0.33 & 0.2 & 0.28 \\
Crystallization temperature (K) & 2327 & - & - & - \\
\hline
\end{tabular}




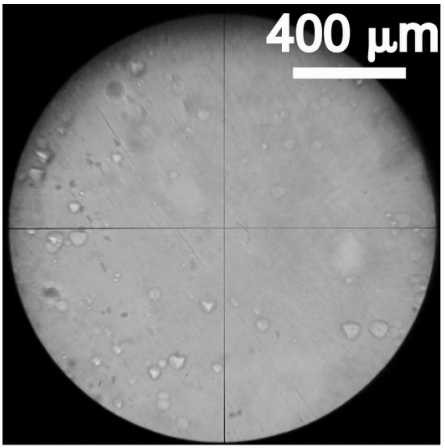

b
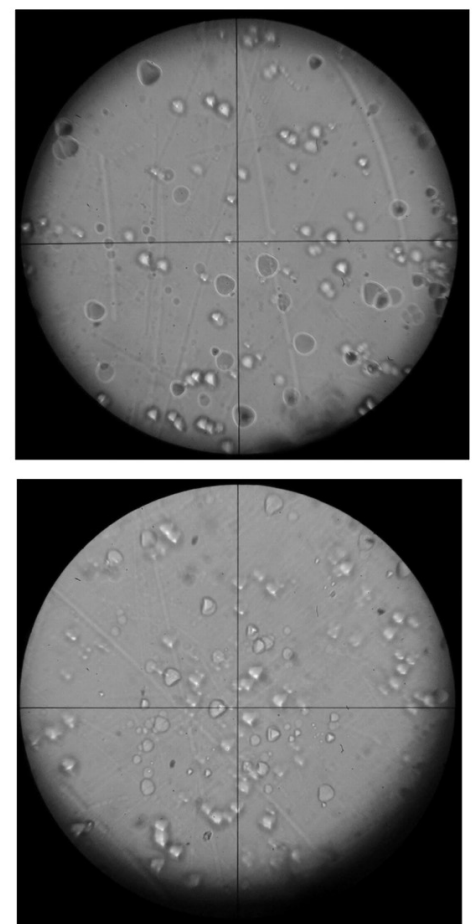

$$
\rho=1 \times 10^{3} \mathrm{~cm}^{-2}
$$

$\rho=4-6 \times 10^{3} \mathrm{~cm}^{-2}$

$\rho=0.8-1 \times 10^{4} \mathrm{~cm}^{-2}$

$$
\rho=4-6 \times 10^{3} \mathrm{~cm}^{-2}
$$
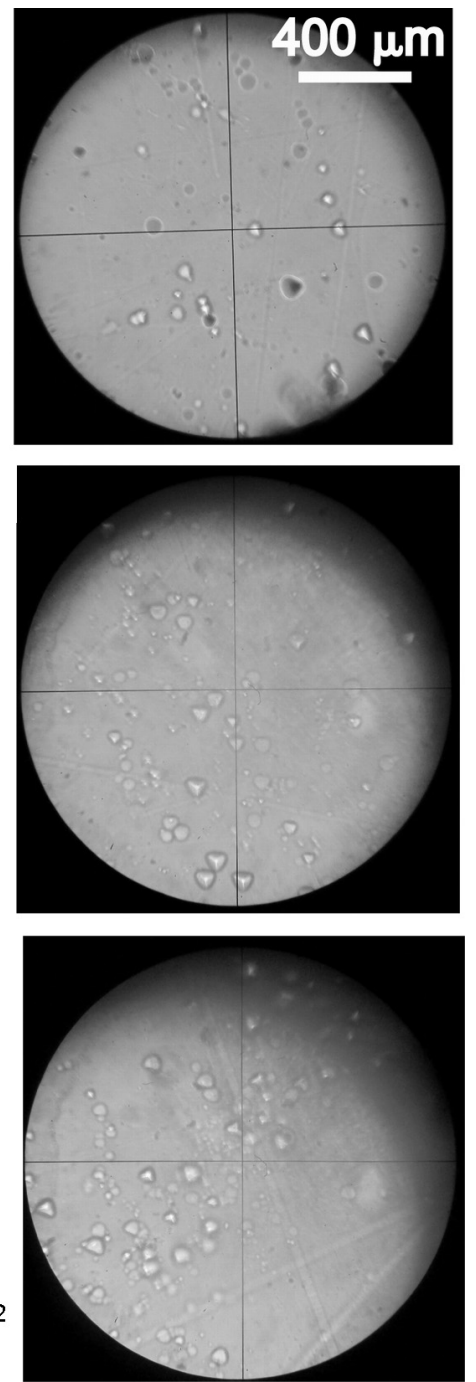

Fig. 4. Distribution of dislocations in the crystal bulk before (from the left) and after (from the right) the correction of the growth conditions: at the onset of crystal growth (a); before the stationary growth (b); at the stationary growth (c).

bution in a flat layer [10]) caused by intense heat withdrawal from the hot zone by a flow of thermal radiation. The crystallization front is non-orthogonal with respect to the crucible bottom. This is explained by more intense heat supply by the heater from above and the shielding action of the bottom plate from below. As follows from the calculations, nonlinearity of the thermal field in the crystal is most essential at the change-over from the triangular to the rectangular part of the crystal, i.e. at the onset of the stationary growth (Fig. 2) where two opaque boundaries (the crucible walls) join. Experience shows that in most cases the formation of block boundaries is observed just in this part of the crystal. Non-uniform temperature distribution may be caused by an essential variation of the shielding efficiency at the change-over from the triangular to the rectangular part of the crucible. According to the performed calculations, additional shielding in this segment considerably reduces non-uniformity of the thermal field and, consequently, the value of thermoelastic stresses. The required shielding conditions were estimated on the base of the determination of the boundary conditions at the change-over from the triangular to the rectangular part of the crystal. Presented in Fig. 3 are the results of comparative calculations of the temperature field and stress field patterns ( $\sigma_{2}$ isolines) in the grown crystal for the cases of the standard shielding (a) and additional shielding in the region of the change-over from the triangular to the rectangular part of the crucible (b). Fig. 3(c) shows $\sigma_{2}$ values in the 
vicinity of the crystallization front before and after the change of the shielding. As is seen, $\sigma_{2}$ is lower in the case of additional shielding, especially near the crucible walls.

After modeling and estimating the probability of dislocation gliding, the temperature gradients $\left(G^{\mathrm{a}}, G^{\mathrm{h}}\right.$ and $\left.G^{\mathrm{v}}\right)$ and the pulling rate were changed in the process of crystal growth, an additional shield was used in the region of the change-over from the triangular to the rectangular part of the crystal.

The results of selective etching of the crystals realized before and after varying the growth conditions testified that before the onset of the stationary growth essential distinctions in the density of the dislocations and their distribution were not observed (Fig. 4, a, b). Thereat, the dislocation density monotonously increased. During the stationary growth under unchanged thermal conditions the dislocation density continued to rise. The segments with low dislocation density interchanged with those containing pronounced dislocation aggregations (Fig. 4, c), but the distribution of dislocations over the crystal was chaotic. After the correction of the thermal growth conditions the dislocation density remained unchanged, but there were observed some changes in the dislocation distribution in this part of the crystal. The dislocation aggregations were located along certain directions (Fig. 4, c).

\section{Conclusions}

The performed investigation allowed to establish the optimum values of the axial, horizontal and vertical components of the temperature gradient $\left(G^{\mathrm{a}}, G^{\mathrm{h}}\right.$ and $\left.G^{\mathrm{v}}\right)$ at the growth of large-size sapphire single crystals by the method of horizontally directed crystallization, as well as to correct the crystal growth rate. Using additional shielding, there was reduced non-uniformity of the thermal field distribution in the crystal, especially in the region of the changeover from the triangular to the rectangular segment. The obtained results made it possible to grow $350 \times 500 \times 45 \mathrm{~mm}^{3}$ sapphire crystals with the surface orientation (10 $\overline{1} 2)$ which did not contain macroblocks. The structural characteristics of the crystals with the surface orientation (0001) were improved.

\section{References}

1. E.R.Dobrovinskaya, L.A.Litvinov, V.V.Pishchik, Encyclopedia of Sapphire, STC Institute for Single Crystals, Kharkov (2004) [in Russian].

2. S.I.Baholdin, V.M.Krimov, Yu.G.Nosov et al., Kristallografia, 55, 749 (2010).

3. Patent Ukraine No.18923A (1997).

4. I.V.Deshko, A.Ya.Karvatsky, Yu.V.Lohmanets, Mathem. Simul., 19, 39 (2008).

5. V.Zdanov, S.N.Rossolenko, V.A.Borodin, Cryst. Res. Techn., 42, 325 (2007).

6. S.Brandon, J.J.Derby, J. Cryst. Growth, 110, 481 (1991).

7. V.F.Tkachenko, A.Ya.Dan'ko, V.M.Puzikov et al., Functional Materials, 14, 321 (2007).

8. M.M.Chernik, E.R.Dobrovinskaya, Izv.AN SSSR, ser.Fiz., 36, 570 (1972).

9. M.V.Klassen-Neklyudova, E.P.Kozlovskaya, A.A.Urusovskaya, Kristallografia, 15, 1084 (1970).

10. S.Dubitsky, V.Podnos, CADmaster, 6, 17 (2001).

11. ELCUT: Modeling of Two-dimensional Fields by Finite Elements Method, v.5.1, User's Manual, Collector: Manufacturing Cooperative TOP (2003) [in Russian].

\title{
Оптимізація температурних умов при вирощуванні великогабаритних кристалів сапфіру методом ГСК
}

\author{
Л.О.Гринь, О.Т.Будніков, Н.С.Сидельнікова, \\ Г.Т.Адонкін, В.В.Баранов
}

\begin{abstract}
Оцінено ступінь виходу дислокацій з кристала за площинами легкого ковзання в залежності від форми фронту кристалізації за шириною та товщиною кристала. Проведено моделювання розподілення температурного поля у кристалі для двохвимірної моделі. Визначено участки нелінійного розподілення теплового поля за шириною та товщиною кристала. Оптимізовано температурні умови для вирощування великогабаритних $(350 \times 500 \times 45$ $\mathrm{mm}^{3}$ ) кристалів сапфіру методом ГСК. Розглянуто змінення щільності дислокацій та їх розподілення за об'ємом кристала після внесення корекції у технологічний режим вирощування. Показано, що оптимізація осьової, горизонтальної та вертикальної складових градієнта температури призводить до покращення рівномірності розподілення теплового поля на фронті кристалізації після стадії розрощування кристала.
\end{abstract}

